\title{
INNOVATIONS
}

\section{A HyperCard call number directory: Using stacks to find stacks}

\author{
By William P. Kane \\ Reference Librarian \\ Wayne State University
}

Wayne State University Libraries now use a dedicated Macintosh terminal running a custom-built HyperCard stack to assist users in locating items by call number. This automated Call Number Directory leads patrons through a series of questions until the exact floor and stack for a particular call number appear on the screen.

\section{Purpose}

Since WSU unveiled its online catalog LUIS in October 1987, the formerly routine determination of floor location by call number has become more complicated. Users and librarians must answer (at least implicitly) a series of questions before heading to the stacks. The revered Collections Directoryan in-house chart that indicates an item's whereabouts according to its card catalog number and deciphers some quaint card catalog stamps-has been rendered obsolete by the online system. Because WSU hosts DALnet (Detroit Area Libraries network) - a consortium of libraries which participate and whose records appear in the LUIS catalog-users can search WSU's catalog and find call numbers for books in libraries throughout southeastern Michigan. Despite obvious on-screen indications of the holding library and/or any special location within, patrons can ignore such vital information and have been known to search the wrong building's shelves for the books they need.

\section{Description}

Patrons use the Macintosh mouse (no keyboard is required) to click on a series of "buttons" which lead them to a variety of informational "cards" or screens culminating in the on-screen presentation of a digitized floor plan with call number ranges in- dicated on the stacks. Arranged hierarchically, the HyperCard stack explicitly asks patrons to answer the following questions for each call number:

- Did this call number come from LUIS or the card catalog?

-If LUIS, is this a WSU item?

- Which library within WSU is indicated (there are four libraries on campus)?

- Are there any special locations or collections such as Reserves or Documents or Reference?

- Is it a Dewey or LC call number?

- Is the item oversize?

-What is the first letter (or number) of the call number?

Only upon this kind of analysis is the patron shown the particular stack of the particular floor of the particular library for each call number.

Moreover, on-screen warnings about the items in the card catalog (which hasn't been updated since 1981) and in the Dewey collection (WSU switched to LC in 1966) compel the patron to think about looking for more current materials.

\section{Practical information}

The WSU Call Number Directory stack currently consists of 60 cards and $198 \mathrm{~K}$ of memory while the HyperCard utility itself occupies $622 \mathrm{~K}$. For this reason, and since opportunities for revising and expanding the Call Number Directory stack are virtually limitless, a Macintosh SE hard disk is recommended. WSUL's terminal is installed prominently among the main library's other OPAC terminals in the reference area. Ideally, patrons can move from the LUIS terminal to the Macintosh to the shelf.

The program is designed for automatic loading 
using the Mac's "Start up" program and by embedding a script into HyperCard's Home stack that goes to the desired card upon opening. Thus, the Call Number Directory stack is enacted merely by turning on the main power switch to the terminal. This is an important programming feature in an environment with many public terminals, each offering different files with different passwords and protocol. Similarly, the machine can be shut down at the click of a well-scripted button enabling Apple's ResCopy tool.

The familiar menubar at the top of the Macintosh screen is easily hidden through "openStack" scripting and, with no keyboard in use, essentially off-limits. Further, since the stack is "browsing" only in the public mode, and since a password is required before any modifications can occur, the stack is protected from tampering. The automated Call Number Directory - turned on in the morning and off in the evening-has an introductory screen that states its purpose and invites patrons to click away.

Simple scripts can be written that keep track of patron use by counting in invisible fields. Peak periods can be similarly identified by comparing these use statistics with the Mac's internal clock.

\section{Use}

Installed with no fanfare or announcement, the terminal has attracted attention-if for nothing other than curiosity. A Macintosh in an IBMdominated area demands attention despite its competitively small screen size and lack of color. The presence of even imperfect graphics compares favorably to the lack of same in the online and CDROM terminals. The Reference and Information Desk staffs have been gradually introducing patrons to the terminal's function-particularly when faced with the general question of "How do I find books by call number in this library?" Moreover, the program is now being introduced through the Center for Bibliographic Instruction-an of fice which administers BI to all new students through a required one-credit course- to familiarize a new generation of library users with the program.

In the meantime, however, some patrons prefer to bypass the system in favor of asking a quick question of a staff member. Despite an inherent "Short Cut" in the program (which allows users to skip some screens once comfortable with the system), some patrons simply are confounded by the number of questions that must be answered before finding out the correct floor or location. Indeed, the terminal is sometimes abandoned mid-stream. Although scripts are written to bring the program back to its introductory card after a certain amount of inactivity, programmers can make the "Payoff" of the location as exact as possible (down to the exact shelf) to keep the users' attention.

\section{Future}

In a multi-institutional database environment like WSU's online catalog, the HyperCard Call Number Directory could eventually be expanded to include all system-wide libraries' collections. Wayne State University Libraries are currently exploring the possibilities of adding features to the existing program: larger screen, color monitor, touch-screen response. Eventually, these features may evolve into an automated Information Kiosk that includes tours (with floor plans culled from the Call Number Directory), instruction (a required HyperCard BI program is in the final stages of development), and general campus information. Meanwhile, the HyperCard stack is a noticeably innovative alternative to an otherwise mundane transaction.

For further information about the HyperCard Call Number Directory, please contact: William P. Kane, Purdy Library, Wayne State University, Detroit, MI 48202; (313) 577-6439.

\title{
The academic reference librarian: Serving graduates in their job search
}

\author{
By Laura Windsor \\ Reference Librarian \\ Texas State Technical Institute
}

Academic reference librarians will encounter reference questions each quarter or semester from those students who are on the verge of graduating, or have already graduated. They can range from "Do you have any books on how to write a re- sume?" through "Who's hiring in the field of electronics?" to "Do you have some sort of list of companies in the import-export business?" Most of us will show them adequate reference sources, but our role in a student's quest for employment is 